\title{
3D Finite Element Method Analysis of Thermal Asperity of Merged MR Heads
}

\author{
Izumi NOMURA, Tsutomu AOYAMA, Hiroshi KIYONO*, and Isamu SATO \\ Advanced Products Development Center, TDK Corp. \\ *Data Storage Components Business Group, TDK Corp. \\ 2-15-7, Higashi-Ohwada, Ichikawa-shi, Chiba 272, Japan
}

\begin{abstract}
Thermal asperity (TA) response of merged MR heads, due to the momentary contact between the heads and recording media, is simulated by the $3 \mathrm{D}$ finite element method. In this simulation, the thermal conduction and thermal distribution of an MR head, and the TA responses superposed on the read-back signals are numerically simulated.

The result are shown as follows: (a) the simulated TA response closely agrees with the experimental TA response; (b) the simulated TA response decreases drastically when a contact point is more than $5 \mu \mathrm{m}$ away from the MR-element; and (c) the read gap material with high thermal conductivity is very effective on reducing TA responses.
\end{abstract}

Key words: MR heads, thermal asperity, noise.

\section{Introduction}

As a recording density continues to grow higher, more signal gain will be required from the sensor and the head flying height will be lower, therefore more often TA response which is superposed on read-back signals[1] will appear. The heat of TA response is caused by the frictional heat between an asperity on a magnetic disk and an air bearing surface (ABS) of an MR head. The TA responses in read-back signals are electronically abated [2, 3].

This paper describes the simulated results about the thermal conduction and thermal distribution of the MR head on TA responses:

1) Comparison of the experimental results with the simulated results.

2) Influence of the heat source position away from the MR-element on TA responses.

3) Influence of the thermal conductivity of the read-gap material on TA responses.

\section{Analysis models}

Table 1 shows the dimensions of an experimental and simulated MR head. The flying height of an MR head is $51 \mathrm{~nm}$ at a relative speed of $10 \mathrm{~m} / \mathrm{s}$. In this experiment, an isolated asperity with the peak height of around $50 \mathrm{~nm}$ and the top area of around $4 \mu \mathrm{m}^{2}$ is artificially made on a disk[4]. Therefore, a momentary contact between the
Table 1 Dimensions of MR head.

\begin{tabular}{lll}
\hline MR-element & $\begin{array}{l}\text { track width } \\
\text { height }\end{array}$ & $2.0 \mu \mathrm{m}$ \\
& $2.0 \mu \mathrm{m}$ \\
\hline Shield & top & $3.5 \mu \mathrm{m}$ \\
thickness & bottom & $2.0 \mu \mathrm{m}$ \\
\hline Read gap length & $0.26 \mu \mathrm{m}$ \\
\hline
\end{tabular}

Table 2 Thermal constants of materials used in analysis.

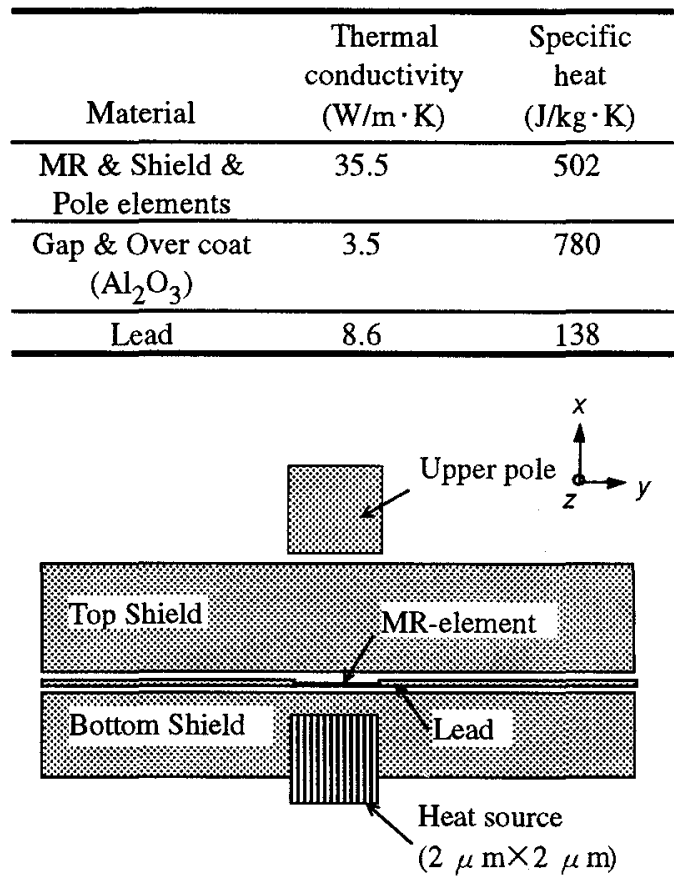

Fig. 1 Simulated model from the top view of the ABS. The origin of the three axes is set at the center of MR-element.

asperity and the $\mathrm{ABS}$ will happen at a relative speed of $10 \mathrm{~m} / \mathrm{s}$.

Table 2 shows the thermal constants of materials used in this analysis. The origin of three axes is set at the center of the MR-element. The volume of the simulated model is around $100 \mu \mathrm{m} \times 100 \mu \mathrm{m} \times 100 \mu \mathrm{m}$, which is sufficient for analyzing the heat distribution of an MR head, using the finite element nonlinear analysis method (FINAS[5], CRC Co. Ltd.). 
Fig. 1 shows the frictional heat model of the MR head from the view of an ABS. The heat induced by a momentary contact between an asperity of media and an $\mathrm{ABS}$ is described in equation(1).

$$
\mathrm{q}=\mathrm{fN} v / \mathrm{A}
$$

where

$$
\begin{aligned}
& \mathrm{q}=\text { heat produced per unit area per unit } \\
& \quad \text { time }\left(\mathrm{W} / \mu \mathrm{m}^{2}\right) \\
& \mathrm{f}=\text { coefficient of friction } \\
& \mathrm{N}=\text { mean impact stress }(\mathrm{N}) \\
& \mathrm{v}=\text { relative } \operatorname{speed}(\mathrm{m} / \mathrm{s}) \\
& \mathrm{A}=\text { contact } \operatorname{area}\left(\mu \mathrm{m}^{2}\right)
\end{aligned}
$$

In this analysis, the values of $\mathrm{f}=0.2, \mathrm{~N}=0.015 \mathrm{~N}, \mathrm{v}=10 \mathrm{~m} / \mathrm{s}$, $\mathrm{A}=4 \mu \mathrm{m}^{2}$ are assumed. The shape of the heat source is given as a rectangular on the ABS in this model. The period of induced heat is assumed to be 20nsec.

The MR-element is modeled as one layer. The temperature rise of this MR-element is translated to the resistance change after averaging the whole MR-element, where the thermal coefficiency of the MR-element is set to be $0.22 \% /{ }^{\circ} \mathrm{C}$ in this analysis. For comparing this resistance change to the read-back signal, the resistance change is translated to the "Thermal noise", which is described in equation (2).

Thermal noise $=\Delta R_{\mathrm{TA}} / \Delta R_{\mathrm{s}}$ where

$$
\begin{aligned}
\Delta \mathrm{R}_{\mathrm{TA}}= & \text { resistance change of MR-element due to TA } \\
& \text { response (\%) } \\
\Delta \mathrm{R}_{\mathrm{S}}= & \text { resistance change of MR-element due to } \\
& \text { peak-to-peak read-back signal (\%), which is } \\
& \text { assumed to be } 0.27 \% \text { in this analysis. }
\end{aligned}
$$

\section{Results and Discussion}

\section{A. Comparison of the experimental results with the simulated results}

In this simulation, the heat source position is set at $\mathrm{x}=$ $-1.6 \mu \mathrm{m}$, as shown in Fig 1. This position represents the center point of rectangular heat source. Fig. 2 shows the experimental and the simulated thermal noise. The origin of the time axis corresponds to the start point for the rise of thermal noise. Both the experimental and the simulated thermal noises increase sharply in $0.07 \mu \mathrm{sec}$, and decrease exponentially after reaching peak values over $2 \mu \mathrm{sec}$. The peak value of the simulated thermal noise is about $40 \%$ higher than that of the experimental value. The reasons are assumed that in this simulation, the heat capacities may be lower and the impact stress may be higher than the actual value.

Fig. 3 shows the simulated and the experimental thermal noise, which are normalized by each peak value shown in

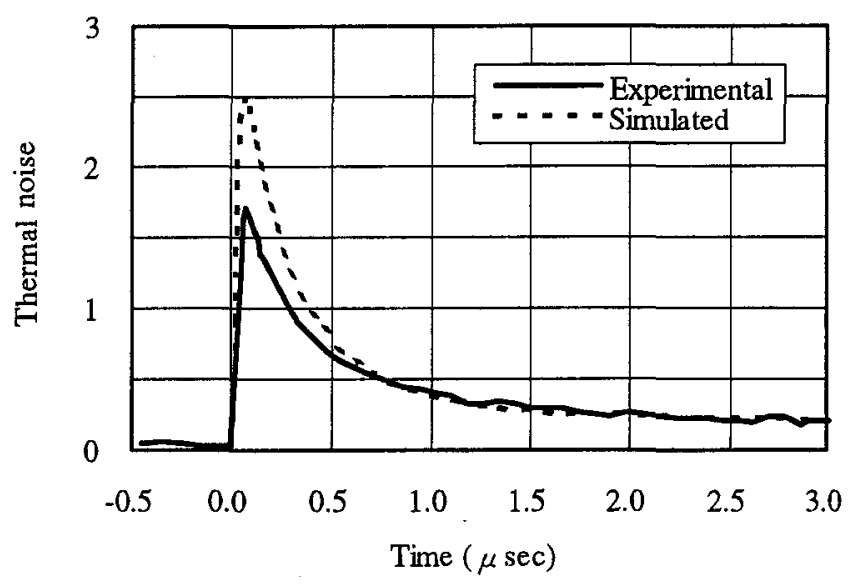

Fig. 2 Comparison of an experimental result of thermal noise with a simulated result.

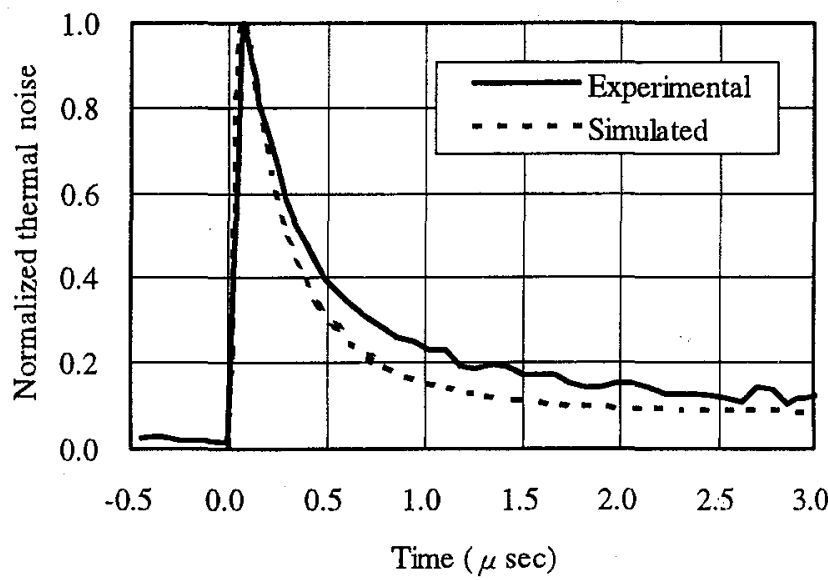

Fig. 3 The simulated and the experimental normalized thermal noise, normalized by each peak value on Fig.2.

Fig. 2. The simulated wave form of normalized thermal noise closely agrees with that of experimental result. Therefore, this simulated thermal model is supposed to be in accordance with the experimental result.

The simulated temperature distribution for the MR head is shown both in Fig. 4 and Fig. 5, at the peak value of the simulated thermal noise. It is found that the maximum temperature rise at the rectangular heat source on an $A B S$ is $40^{\circ} \mathrm{C}$. Besides the maximum temperature rise at the MR-element $1.6 \mu \mathrm{m}$ away from the heat source is $6^{\circ} \mathrm{C}$ and mean temperature rise of the whole MR-element is $3^{\circ} \mathrm{C}$.

\section{B. Influence of the heat source position away from the $M R$ - element on TA responses}

Fig. 6 shows the simulated thermal noise, where the parameter is the heat source position from the MR-head, 


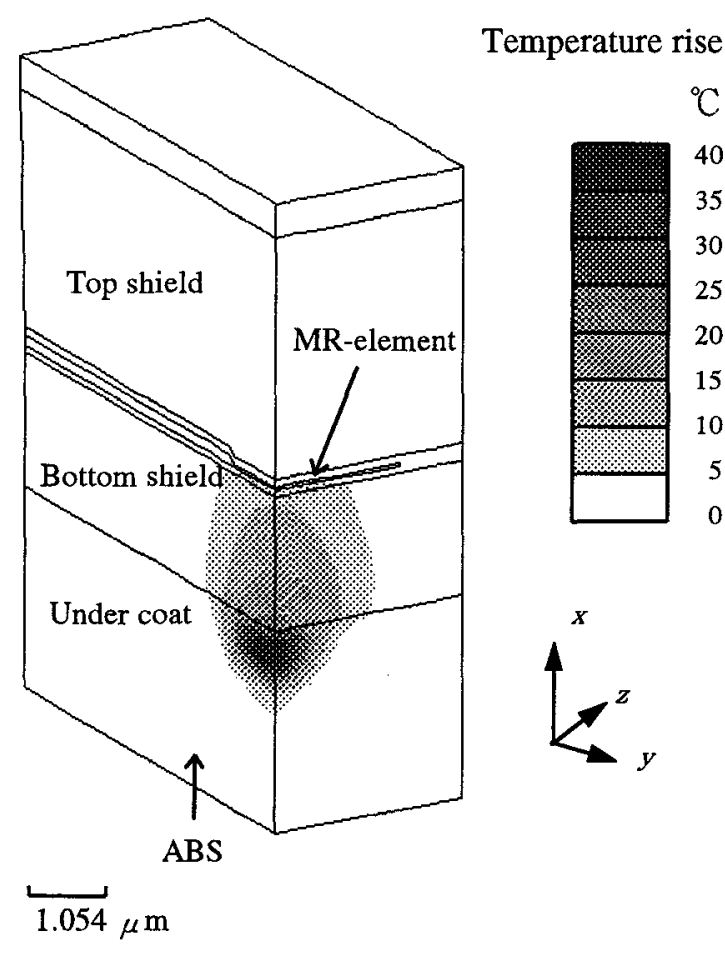

Fig.4 Simulated temperature distribution in the MR head at the peak of thermal noise, the position of heat source is $\mathrm{x}=-1.6 \mu \mathrm{m}$.

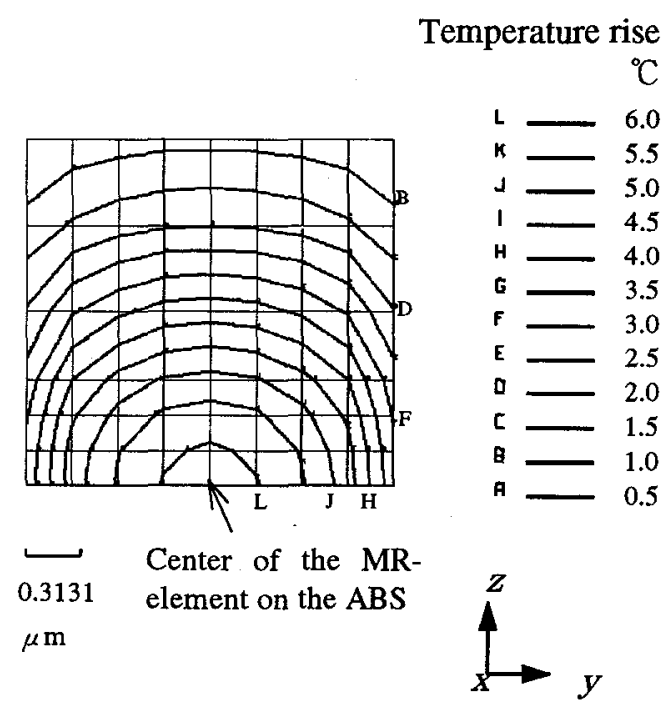

Fig.5 Simulated temperature distribution in the MR-element at the peak of thermal noise, the position of heat source is $\mathrm{x}=-1.6 \mu \mathrm{m}$.

along the $\mathrm{x}$ axis. The origin of the time axis corresponds to the start point of heat generation. It is found that the delay of the rise up point for the thermal noise takes longer with the increase in distance from the MR-

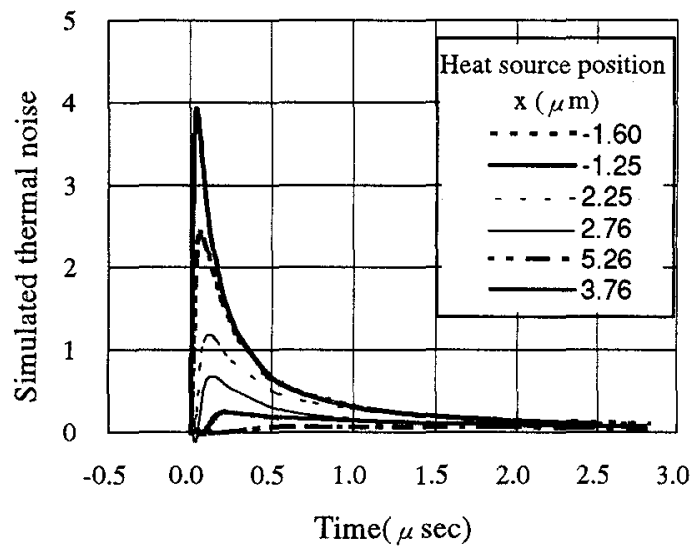

Fig. 6 Simulated thermal noise, where the parameter is the heat source position away from MR head.

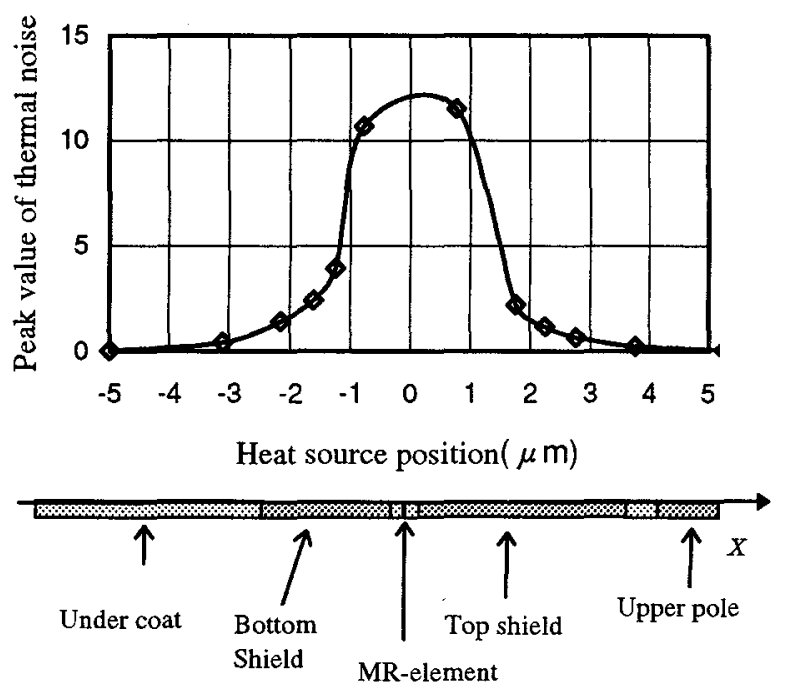

Fig. 7 Peak value of the simulated thermal noise as a function of the heat source position away from the MR head.

element. If the heat source position is set to within $4 \mu \mathrm{m}$ away from the MR-element, the value of thermal noise sharply increases and exponentially decreases with an increase in time. On the other hand, if the heat position is set more than $5 \mu \mathrm{m}$ away from the MR-element, the value gradually increases and decreases with an increase in time.

Fig. 7 shows the peak value of the simulated thermal noise, as a function of heat source position away from the MR-head. If the heat position is set more than $5 \mu \mathrm{m}$ away from the MR-element, the peak value of the thermal noise reduces drastically. 


\section{Influence of the thermal conductivity for the read-} gap material on TA responses

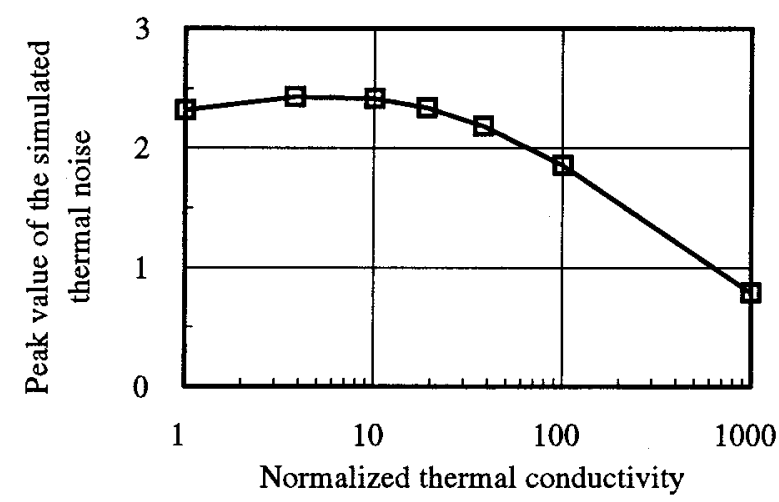

Fig. 8 Peak value of the simulated thermal noise as a function of the normalized thermal conductivity for read gap material. The heat source position is $x=-1.6$ $\mu \mathrm{m}$.

Fig. 8 shows the peak value of the simulated thermal noise as a function of the thermal conductivity for the read gap material, where the thermal conductivity is normalized by the value of $\mathrm{Al}_{2} \mathrm{O}_{3}(3.5 \mathrm{~W} / \mathrm{m} \cdot \mathrm{K})$. The peak value of the simulated thermal noise changes little in the normalized thermal conductivity from 1 to 10 , and sharply decreases with an increase in the normalized thermal conductivity range of more than 10 . From these results, the adaptation of the read gap material with the higher thermal conductivity of more than 100 is much more effective for suppression of the TA responses.

\section{Conclusion}

The simulated model of the TA responses in the MR head is developed. The simulated result closely agrees with the experimental result. The simulated TA response decreases drastically when a contact point is more than $5 \mu$ $\mathrm{m}$ away from the MR-element. In addition, the read gap material with high thermal conductivity is very effective on reducing the TA responses.

\section{Acknowledgments}

The authors would like to thank Executive Managing Director S. Saitoh and Executive Director J. Ezaki of TDK Corporation for their encouragement and support of this work.

\section{References}

[1]E. Sawatzky, "Thermal signals in MR heads due to Asperity contacts", INTERMAG'90, FP-12.

[2]K. B. Klassen, "Electronic Abatement of Thermal Interference in (G)MR Heads Output Signals", Digests of INTERMAG '97, CC-01.

[3]W. Ye, "A Study on Eliminating the Effect of Thermal Asperity of MR Heads in Tape Drive", Technical Report of IEICE, MR96-45, Nov. '96.

[4]Li Y., Kumaran A.R, "The Determination of Flash Temperature in Intermittent Magnetic Head/Disk contacts Using Magnetoresistive Heads: Part I", ASME Vol.115, p.170-178, '93.

[5]K. Iwata, "Development and Utilization of the FINAS General Purpose Nonlinear Structure Analysis System", PNC Technical, No.76, Dec.'90. 